Annals of Glaciology 61985

(C) International Glaciological Society

\title{
MEASUREMENTS OF DAILY VARIATIONS IN THE SUBSURFACE WETNESS GRADIENT
}

by

\author{
A. DENoth AND A. Foglar
}

Department of Physics, University of Innsbruck, A-6020 Innsbruck, Austria

\begin{abstract}
A flat condenser in strip-line technique has been developed to measure the gradient in liquid water content near the snow surface. This dielectric sensor is connected to a twin-T-bridge with an operating frequency of $27 \mathrm{MHz}$. The special design of the sensor allows the non-destructive measurement of the mean dielectric constant of underlying material at two different depths of 0 to $2 \mathrm{~cm}$, and of 2 to $4 \mathrm{~cm}$ below the snow surface. Based on the model of Polder and van Santen, changes in the gradient of liquid water content can be calculated from measured changes in the dielectric constant in different depths; the density has to be measured separately. Results of measurements of wetness gradient with this flat capacitative sensor are given. Field measurements have been carried out in the Stubai Alps (3100 m a.s.1.) and at the Hafelekar (2256 m a.s.1.) near Innsbruck.
\end{abstract}

\section{INTRODUCTION}

Liquid water content determines many of the physical characteristics of snow, so a precise, efficient and preferably non-destructive wetness measuring technique is needed. Experimental observations of the microwave backscattering coefficient of snow cover show a high sensitivity to wetness in the uppermost layer (Stiles and Ulaby 1980, Mätzler and others 1984). Measurements of thermal radiation by passive microwave radiometers also show a dependence on moisture profiles (Johnson and others 1982).

For the special case of measuring the liquid content in a thin layer of approximately $3.5 \mathrm{~mm}$, a comb-shaped condenser with a total sensor surface of 4 x $4 \mathrm{~cm}^{2}$ was previously developed (Ambach and Denoth 1980). This paper describes a new dielectric sensor designed to measure surface and bulk permittivity simultaneously.

\section{SENSOR DESIGN AND ELECTRONICS}

The geometry of the sensor has been designed especially (Foglar 1983) to allow a non-destructive measurement of the dielectric profile of a snow cover in a top-layer of approximately $4 \mathrm{~cm}$, and to account for a sufficiently large and representative measuring volume, i.e. to average over a large number of snow grains or grain clusters. Figure 1 shows a schematic view of the sensor geometry with dimensions. Rf-power of $27 \mathrm{MHz}$ is fed in at $A$ and is applied only to the inner pair of conducting stripes when switches $S_{1}$ and $S_{2}$ are open. In this operating mode, the sensor is sensitive to dielectric properties in a layer of approximately $2 \mathrm{~cm}$ thickness. In the second operating mode, when the switches $S_{1}$ and $S_{2}$ are closed, the inner and outer co-planar stripes are electrically in parallel and the sensor senses dielectric properties in a layer of approximately $4 \mathrm{~cm}$ in thickness. So sensor geometry and therefore also the penetration depth of the electric field lines, given by the effective width and spacing of the rf-operated stripes, can be changed by switching $S_{1}$ and $S_{2}$. Sensor electronics consist of a twin-T-bridge, a rf-oscillator $(27 \mathrm{MHz})$ and a signal processing and display unit: for a block diagram see Figure 2. The tuning operation of the bridge and the change in the operating mode of the sensor is made by

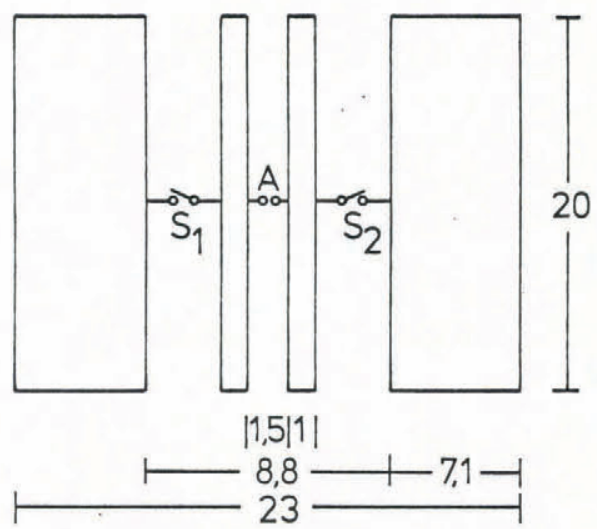

Fig.1. Schematic view of the sensor plane, dimensions in $\mathrm{cm}$. For a measurement, the sensor plane is applied to the snow surface.

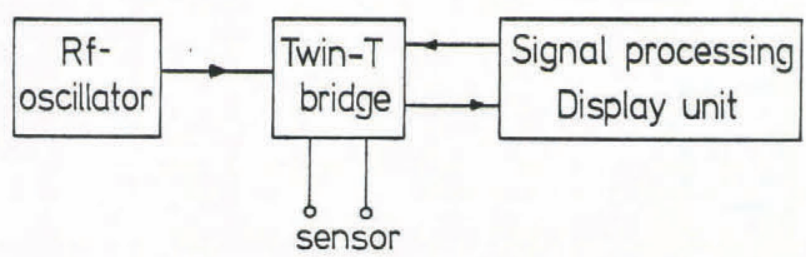

Fig.2. Block diagram of the sensor electronics.

varying dc-levels only. Sensor electrodes are attached to a block of plexiglass to provide a good contact to the snow cover; no significant densification occurs.

\section{MEASUREMENTS OF WETNESS GRADIENTS}

Measurements of dielectric profile and wetness gradient using the flat dielectric sensor have been made in the natural snow cover in the Stubai Alps and at the Hafelekar near Innsbruck, Austria. Snow wetness profile is calculated from the dielectric profile by applying the model of Polder and van Santen (cf. Denoth 1980). For comparison, the mean liquid water content in a layer extending from the surface to a depth of $11 \mathrm{~cm}$ was measured by an absolutely calibrated snow moisture meter using a plate condenser as sensor.

Daily variations in the surface wetness $(0$ to $2 \mathrm{~cm}$, solid line), in a deeper layer of 2 to $4 \mathrm{~cm}$ (broken line) and also in a layer extending from 4 to $11 \mathrm{~cm}$ (dotted line) are shown in Figure 3. The measurements were made at the Hafelekar and cover the period from 13 June $1984,13: 30$ to 14 June, 14:00. The mean liquid content in the layer 4 to $11 \mathrm{~cm}$ is calculated from the directly measured value $(0$ to $11 \mathrm{~cm})$ of the absolutely calibrated snow moisture meter and the measured liquid water contents in the layers 0 to $2 \mathrm{~cm}$ and 2 to $4 \mathrm{~cm}$. Typical error bars are also shown. Large fluctuations in snow wetness in the uppermost layer are due to rapid changes in ambient conditions (wind, temperature, 


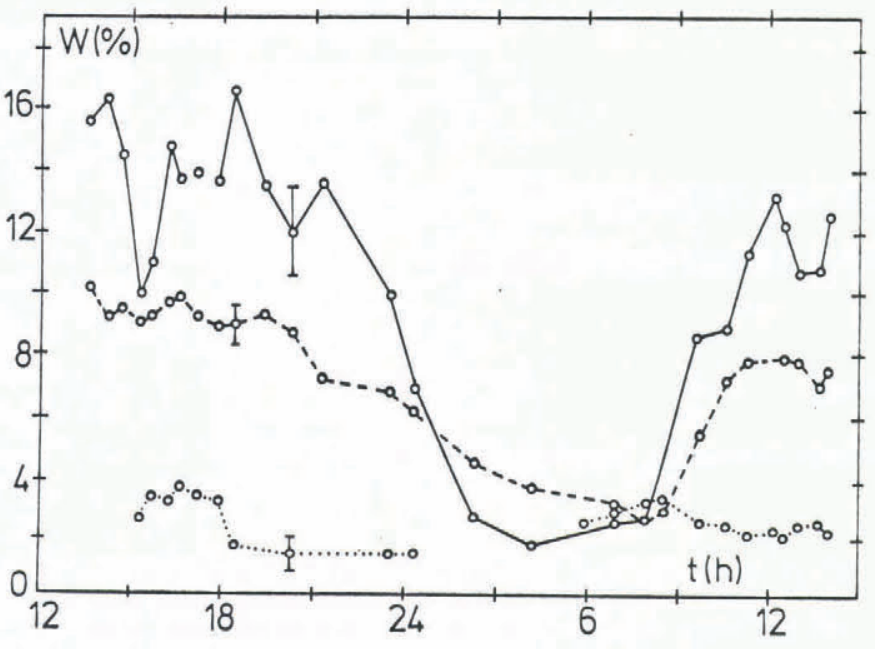

Fig.3. Change in snow wetness in 3 different layers during a 24-hour measurement from 13:30, 13 June to 14:00, 14 June in 1984. The solid line represents the wetness in the 0 to $2 \mathrm{~cm}$ layer, the dashed line in the 2 to $4 \mathrm{~cm}$ layer, and the dotted line in the 4 to $11 \mathrm{~cm}$ layer. Typical error bars are shown.

cloudiness). In the adjacent layer a lower wetness appears (negative wetness gradient), except during the night-time from 01:00 to 07:30, where the top layer shows a lower liquid water content (positive gradient) Wetness in the 4 to $11 \mathrm{~cm}$ layer shows only small variations. Increase in surface wetness beginning at 08:00 and in the 2 to $4 \mathrm{~cm}$ layer beginning at $08: 30$ is caused by incoming solar radiation (local sunrise at 08:06). Corresponding variation in the wetness gradient is shown in Figure 4. The surface layer (solid line) shows a large variation in (negative) wetness gradient during the

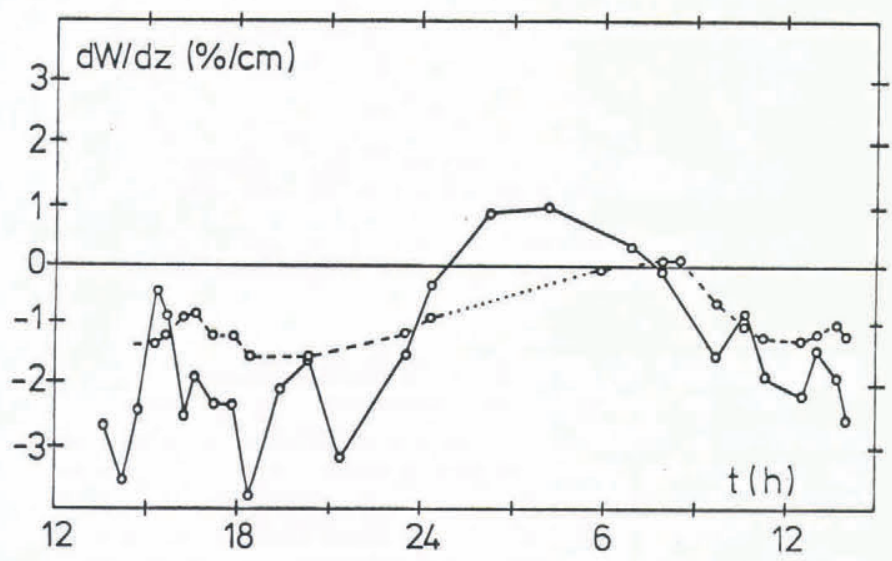

Fig.4. Daily variations in wetness gradient (in $\%$ by vol $/ \mathrm{cm}$ ) derived from the measurements shown in Figure 5. The solid line represents the gradient of the top layer, the dashed line the gradient of the underlying region.

daytime and an inversion (positive gradient) at night from approximately 01:00 to 07:30. Variations in gradient in the deeper region (broken line) are not so marked, and are slightly retarded compared to the course of the

\section{ACKNOWLEDGEMENTS}

This research was supported by the Austrian "Fonds zur Förderung der wissenschaftlichen Forschung", Grant no 3888. Field measurement was supported in part by the Wintersport Tirol AG, Innsbruck, Austria.

\section{REFERENCES}

Ambach W, Denoth A 1980 The dielectric behaviour of snow: a study versus liquid water content. In Rango A (ed) NASA Conference Publication 2153: 69-92
Denoth A 1980 Thependular-funicular liquid transition in snow. Journal of Glaciology 25(91): 93-97

Foglar A 1983 Entwicklung eines Schneefeuchte-Meßgerätes zur Wassergehaltsbestimmung in dünnen Schichten. Diploma thesis, University of Innsbruck, Austria

Johnson E R, Peck E L, Keefer T N 1982 Combining remotely sensed and other measurements for hydrological areal averages. NASA Contractor Report 170457

Mätzler C, Aebischer H, Schanda E 1984 Microwave dielectric properties of surface snow. Journal of Oceanic Engineering OE-9 (5): 366-371

Stiles H, Ulaby F T 1980 Radar observations of snowpacks. In Rango A (ed) NASA Conference Publication 2153: $131-146$ 